\title{
MILLIKAN EXPERIMENT ANALYSIS
}

\author{
Héctor G. Riveros \\ Universidad Nacional Autónoma de México \\ riveros@fisica.unam.mx
}

\begin{abstract}
Millikan experiment demonstrated the quantization of the electron charge and measured its magnitude. Millikan experiment is repeated in school laboratories, mostly with disappointing results. However, it is interesting to interpret the data presented by Millikan at his reception of the Nobel Prize and in an article in Physical Review. He spent many years perfecting the experiment, reducing convection currents and changed to oil drops to reduce the evaporation. The best data corresponded to drops so small that it took them 120 seconds to fall 1,303 cm, values that correspond to the presence of 1 to 4 electrons in a drop. However, in school laboratories, times as short as 3 to 10 seconds are routinely obtained, corresponding to the charges of tens of electrons per drop to overcome gravity. Such time, therefore, demand a very high precision in the measurement of speeds, seldom available in a typical school environment.
\end{abstract}

KEYWORDS: Millikan, experiment, analysis

\section{INTRODUCTION}

In 1897, J.J. Thomson discovered the electron as a particle and found its charge/mass ratio to be $\mathrm{q} / \mathrm{m}=1,756 \times 1011 \mathrm{C} / \mathrm{kg}$. Thomson's discovery started a "race" to measure the electric charge of the electron. It was then that R.A. Millikan designed his famous experiment that was perfected over several years. His best data was presented in his Nobel Prize acceptance speech ${ }^{1}$ with an oil drop that fell $1.3 \mathrm{~cm}$ in a time of 120 seconds. He had previously published ${ }^{2}$ other results with falling drops times between 12 to 19 seconds. He demonstrated the quantization of the electron charge and measured its value. This classic experiment is done in thousands of physics teaching laboratories around the world. Melissinos in his book ${ }^{3}$ describes it and, likewise, many other articles suggest how to improve student experiments. Kapusta ${ }^{4}$ while calculating the propagation of errors suggests that the best results are obtained for falling times close to 10 seconds, not realizing that such falling times do require several electrons/drop. Nowadays, the use of digital video ${ }^{5}$ helps to improve timing accuracy. Heald ${ }^{6}$ proposes measuring the drop time and voltage to keep the drop floating in the air. Jones ${ }^{7}$ proposes to use a computer to quickly interpret the data and calculate the radius of the drop and its charge. Halyo et $\mathrm{al}^{8}$ do a systematic search of fractional charges using modern resources, it is a very good investigation.

\section{Experiment}

Basically, the experiment involves letting charged drops fall between two horizontal metal plates connected to a variable electric potential source. Without establishing any potential difference between them, the drops fall with a terminal speed calculated assuming a viscous friction of Stokes, until the frictional force equals its weight: 


$$
\mathrm{mg}=6 \pi \eta \mathrm{aVf}=\mathrm{cVf}
$$

where $\mathrm{m}$ is the mass, " $\mathrm{g}$ " the acceleration of gravity, $\eta$ the viscosity, " $a$ " the radius of the drop," $\mathrm{c}$ " is a constant and Vf the rate of fall. When the voltage is applied, an electric force appears that rises it to its original height. The forces are now:

$$
\mathrm{qE}-\mathrm{mg}=6 \pi \eta \mathrm{aVr}=\mathrm{cVr}
$$

where $\mathrm{q}$ is the electric charge, $\mathrm{E}$ is the electric field and $\mathrm{Vr}$ is the terminal rise speed. Using the constant $\mathrm{c}$ for friction avoid using Stokes's law, whatever the friction is, the electric charge is proportional to the sum of velocities $\mathrm{Vf}+\mathrm{Vr}$.

Combining 1 and 2 we get:

$$
q=(6 \pi \eta a / E)(V f+V r)=k(V f+V r)=c(V f+V r) / E
$$

where the constant $\mathrm{K}=\mathrm{c} / \mathrm{E}$ depends on the viscosity $\eta$, the radius a and the electric field E. Millikan proposes that for drops of size comparable to the mean free path 1 of the air molecules it is necessary to use an effective viscosity calculated as effective viscosity $=\eta /(1+\mathrm{Al} / \mathrm{a})=\eta /(1+\mathrm{b} / \mathrm{pa})$

where $\mathrm{A}$ and $\mathrm{b}$ are constant and $\mathrm{p}$ the atmospheric pressure.

Writing the mass as Volume by density measured in the air, in equation (1), the radius of the drop is:

$\mathrm{r}=3(\eta \mathrm{Vf} / 2 \rho \mathrm{g})^{1 / 2}$

(5

where the viscosity appears, and it is necessary to calculate it considering the effective viscosity.

The experiment begins by producing a cloud of droplets that falls through a small hole in the top plate. They are electrically charged be it by friction or by exposure to Xrays or ultraviolet light. They are observed with a microscope focused on their trajectory and the time it takes to fall between two marks is measured. Turning on the electric field measures the time it takes to rise between the same two marks. The temperature was kept constant to $0.02{ }^{\circ} \mathrm{C}$ to reduce air convection. The data that follows I Table 1 is the one Millikan presented with his best results in his speech of acceptance of the Nobel Prize. ${ }^{1}$

\begin{tabular}{|l|l|l|l|l|}
\hline & T rise $\mathrm{V}$ & $\mathrm{V}$ rise $\mathrm{m} / \mathrm{s}$ & $\mathrm{Vf}+\mathrm{Vr} \mathrm{m} / \mathrm{s}$ & -to+ $\mathrm{m} / \mathrm{s}$ \\
\hline 120.8 & 26.2 & 0.000497 & 0.000606 & 0.000300 \\
\hline 121 & 11.9 & 0.001095 & 0.001203 & 0.000300 \\
\hline 121.2 & 16.5 & 0.000790 & 0.000898 & 0.000302 \\
\hline 120.1 & 16.3 & 0.000799 & 0.000908 & 0.000598 \\
\hline 120.2 & 26.4 & 0.000494 & 0.000602 & 0.000602 \\
\hline 119.8 & 67.4 & 0.000193 & 0.000302 & 0.000602 \\
\hline 120.1 & 26.6 & 0.000490 & 0.000598 & 0.000606 \\
\hline- & 16.6 & 0.000785 & 0.000893 & 0.000893 \\
\hline 120.2 & 16.6 & 0.000785 & 0.000893 & 0.000893 \\
\hline
\end{tabular}




\begin{tabular}{|l|l|l|l|l|}
\hline- & 16.4 & 0.000795 & 0.000903 & 0.000898 \\
\hline 120.2 & 68 & 0.000192 & 0.000300 & 0.000903 \\
\hline 119.9 & 67.8 & 0.000192 & 0.000300 & 0.000908 \\
\hline average & 26.4 & 0.000494 & 0.000602 & 0.001203 \\
\hline 120.35 & & & & \\
\hline
\end{tabular}

Table I

Note the constancy of the fall times and that it takes two minutes to drop $1.303 \mathrm{~cm}$. The constancy indicates the absence of turbulence in the cavity, and the long time tells us how small the drop was. The drop speed Vf in the sum of speeds was taken as its average value. The fifth column shows the sum of ordered speeds from least to greatest. Figure 1 shows the sum of the speeds $\mathrm{Vf}+\mathrm{Vr}$ ordered from lowest to highest in $\mathrm{m} / \mathrm{s}$.

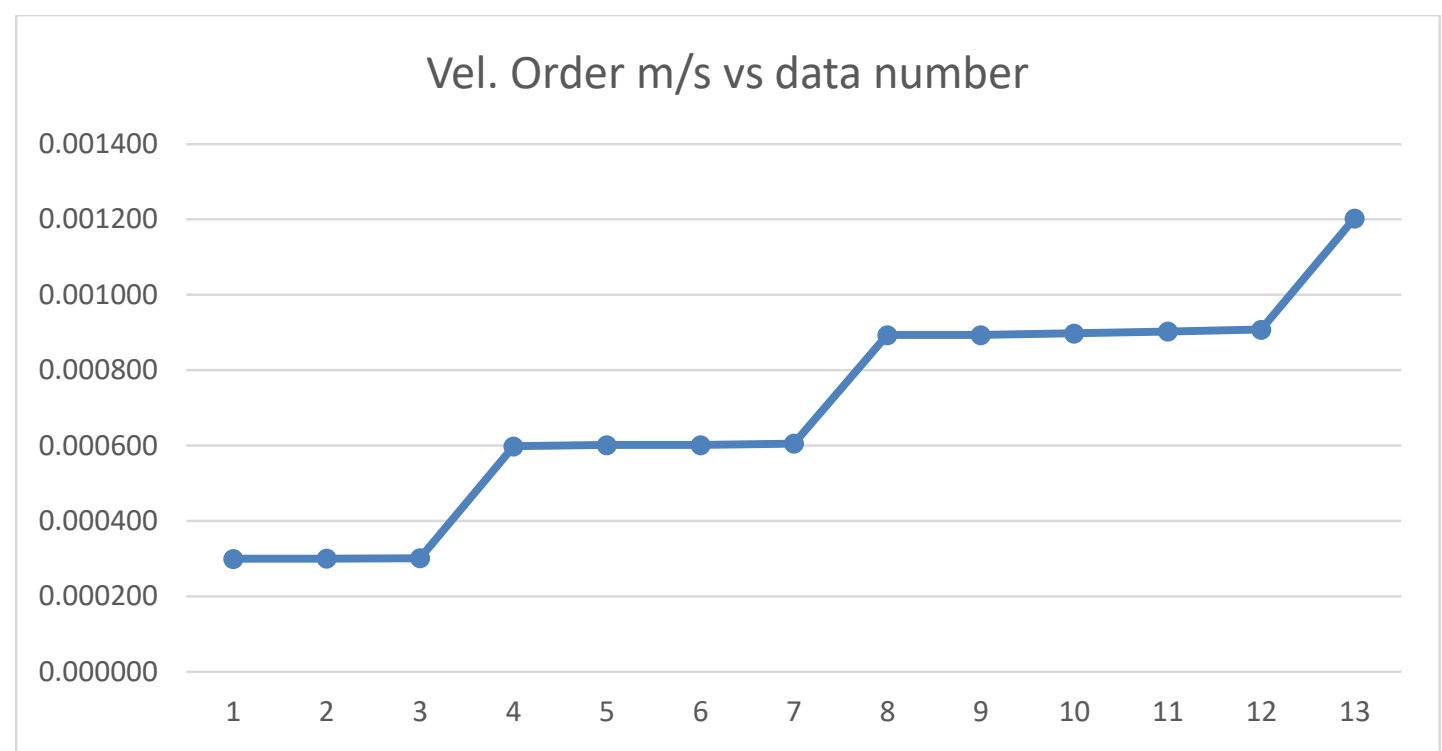

Fig. 1. Speeds Vf $+\mathrm{Vr}$ ordered from lowest to highest in $\mathrm{m} / \mathrm{s}$

This graph demonstrates the quantization of the charge. Millikan gives the distance traveled as $1,303 \mathrm{~cm}$, the electric field at about $6000 \mathrm{~V} / \mathrm{cm}$ but does not mention oil density or air temperature. This prevented us from obtaining the value of the electron charge, but Millikan calculated it as e $=(4,777 \pm 0.005) \times 10^{-10}$ electrostatic charge units. But dividing each sum of speeds by 2,3 or 4 , we obtain 4 values that we can combine $\mathrm{Vf}+\mathrm{Vr}=(3.005 \pm 0.006)^{*} 10^{-4} \mathrm{~m} / \mathrm{s}$, as the average value for an electron. We can calculate the constant $\mathrm{K}$ using the current value of $\mathrm{e}$, and $\mathrm{K}=(5.33 \pm 0.01) \times 10^{-16} \mathrm{Cs} / \mathrm{m}$ is obtained, using the density and temperature of another drop to calculate (3), the viscosity (4) is divided by 1,045 to obtain the measured $\mathrm{K}$. This is the effective viscosity correction. We have data from another drop ${ }^{2}$ taken from his article, in Table II. 
TABLE IV.

Drop No. 6.

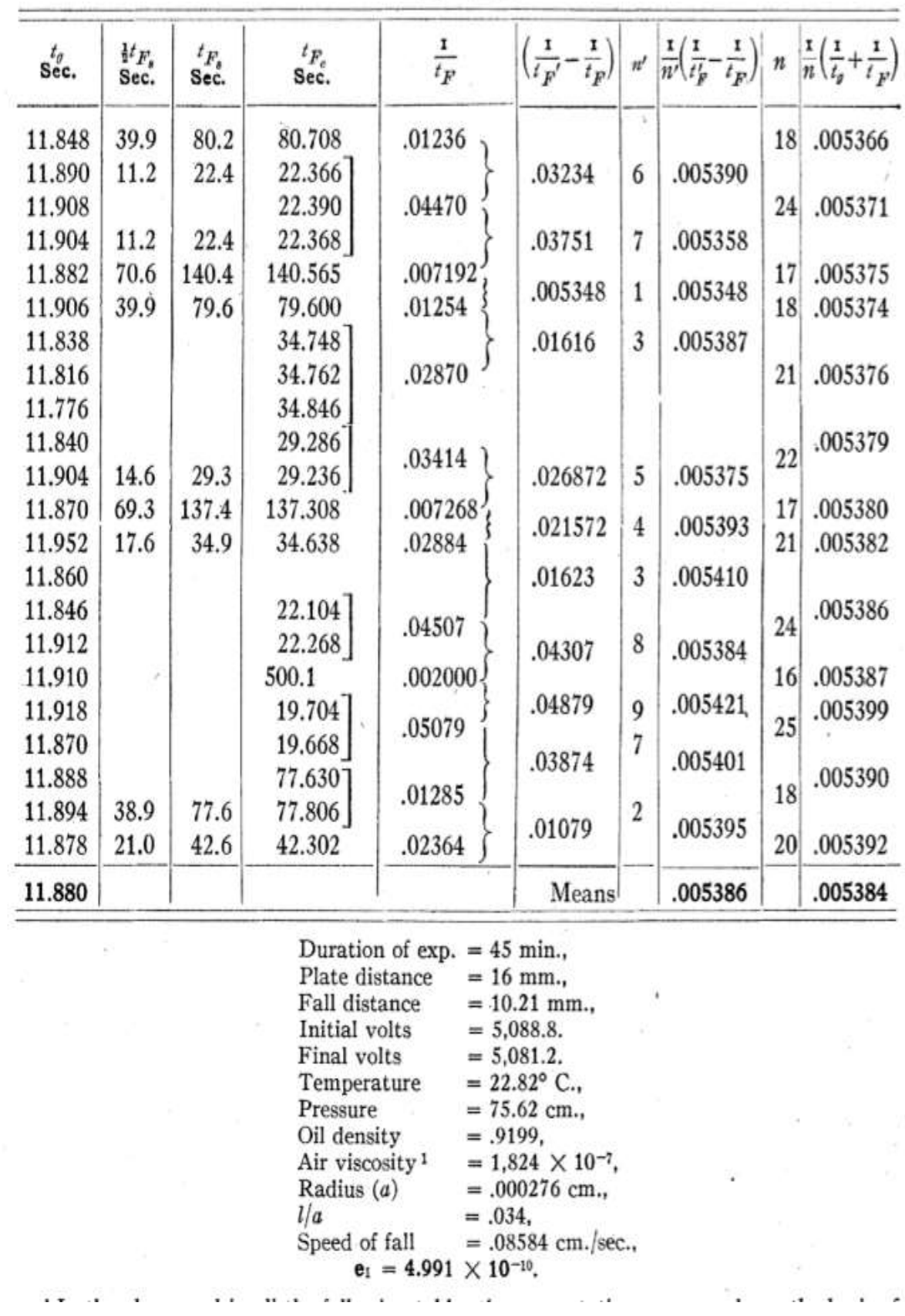

For this drop Millikan obtains e $=4,991 \times 10-10$ electrostatic charge units, a value slightly higher than the real value, accepted value of $4,803 \times 10-10$. The last column is almost $(\mathrm{Vf}+\mathrm{Vr}) / \mathrm{n}$ where $\mathrm{n}$ is the number of electrons in the drop, it needs to multiply by $1.021 \mathrm{~cm}$ which is the fall distance. Note the constancy of this value that has been the sum of speeds for a single electron charge. This column can be written using only the fall and rise times, which is what we did. 
Vol.8, Issue 2, pp.74-81, February 2020

Published by ECRTD- UK

Print ISSN: ISSN 2054-6351

Online ISSN: ISSN 2054-636X

The first column shows the fall times, the second the time to the middle of the fall, the third the time to the total of the fall and the fourth column indicates the rise time measured with a more accurate instrument. Column $\mathrm{n}$ shows the number of electrons calculated by Millikan. We note that the fall times are 10 times lower and now we have the data to calculate the constant $\mathrm{K}$ and the value of the load in each drop. The values in column two are very close to the middle of column 3 indicating that the convection is small. Columns three and four should be the same if we rounded the values in column four to one tenth of a second. When measuring the crossing of the first mark, a delay is introduced due to the speed of the response of the finger, but when measuring the crossing of the second mark, an almost equal delay is introduced. Measuring the period of a pendulum with a manual chronometer is considered normal to a precision of a tenth of a second, when measuring a single oscillation. Currently, measuring thousandths of a second requires cameras of many frames per second.

Reviewing the data of the experiment we noticed that the viscosity of the air at $20^{\circ} \mathrm{C}$ is $1.825 \times 10^{-5} \mathrm{Kg} / \mathrm{ms},{ }^{9}$ which is equal to the $1824 \times 10^{-7}$ mentioned in units $\mathrm{g} / \mathrm{cms}$. The drop speed is $0.08594 \mathrm{~cm} / \mathrm{s}$, different from the mentioned $0.08584 \mathrm{~cm} / \mathrm{s}$. Taking the average fall time, a velocity $\mathrm{Vf}=0.0008594 \mathrm{~m} / \mathrm{s}$ is calculated, which is added to the rising velocities $\mathrm{Vr}$ to obtain their sum. We found that the value $\mathrm{Vo}=5.49 \times 10^{-5}$ allows to find integer values for the quotient $(\mathrm{Vf}+\mathrm{Vr}) / \mathrm{Vo}$, as shown in Figure 2.

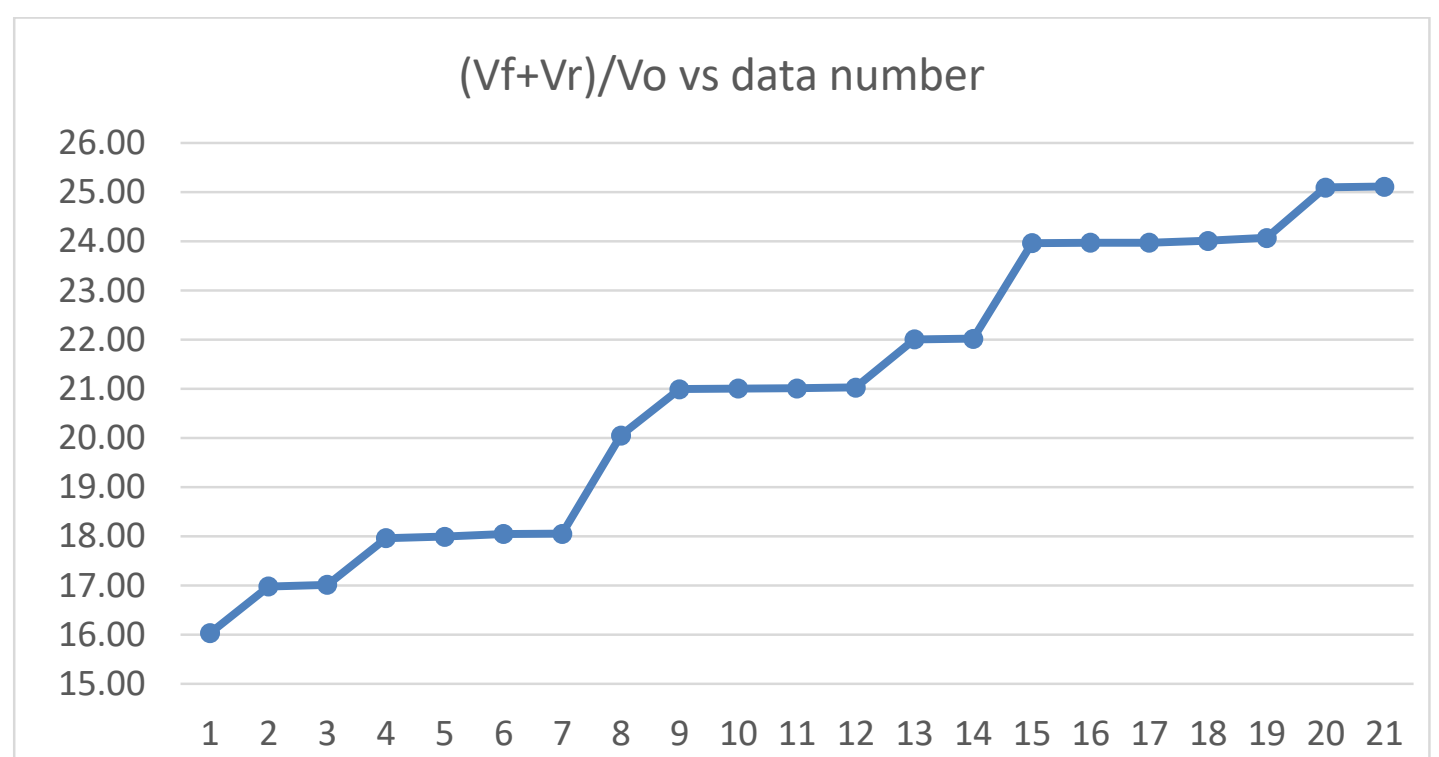

Fig. 2.- The values of the sum $\mathrm{Vf}+\mathrm{Vr}$ are integer multiples of $\mathrm{Vo}$ and indicate the number of electrons in the drop. If the drop has a lot of mass, it requires many electrons to compensate its weight.

The charge in the drop is proportional to this sum, equation (3). The constant of proportionality is $K=(6 \pi \eta \mathrm{a} / \mathrm{E})$. Calculating $\mathrm{K}$ using the MKS values gives: $\mathrm{K}=$ $3.03 \times 10-15 \mathrm{Cs} / \mathrm{m}$ and the charge can be calculated in each drop, but no integer multiples of $\mathrm{e}=1,602 \times 10-19 \mathrm{C}$ appear. Changing to effective viscosity with $\mathrm{A}=0.706$ 
and $1 / \mathrm{A}=0.034$ obtains $\mathrm{K}=2.92 \times 10^{-15} \mathrm{Cs} / \mathrm{m}$ and Figure 3 shows the number of electrons in each drop, using the current value of e.

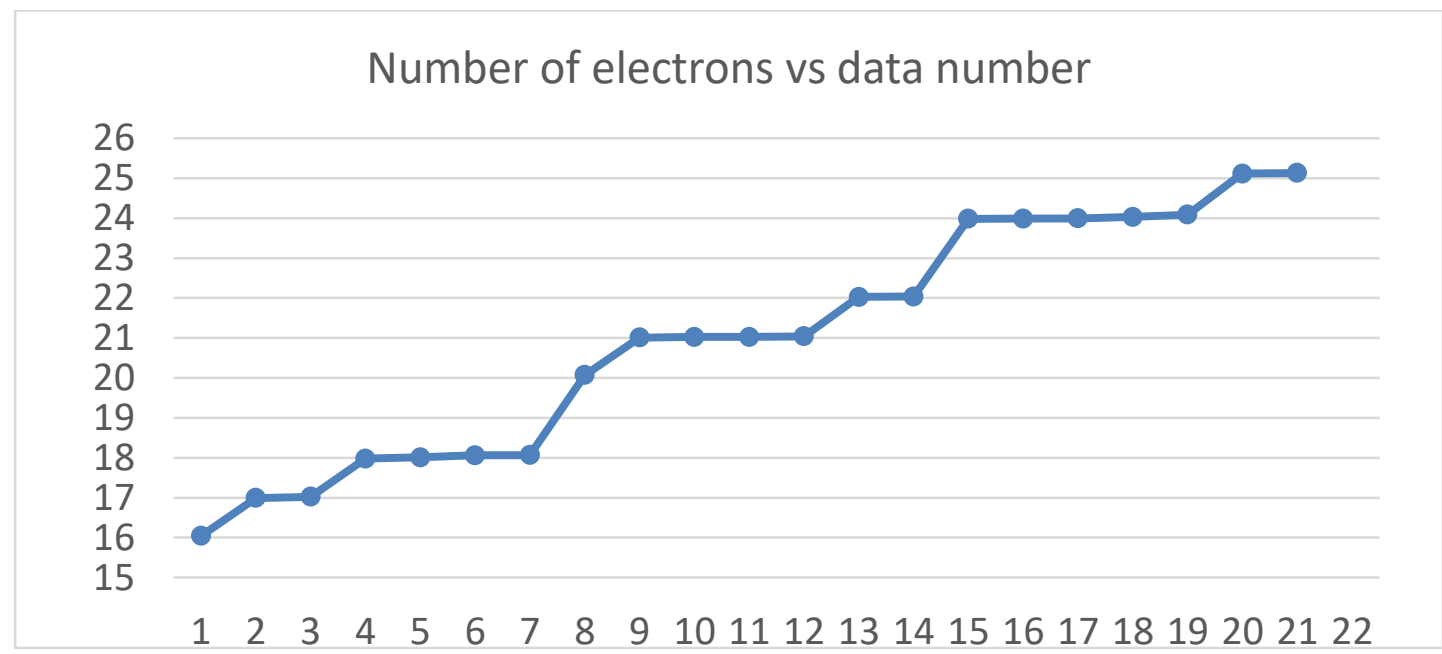

Fig. 3.- Number of electrons for each sum $\mathrm{Vf}+\mathrm{Vr}$, are whole numbers, but it takes at least 16 electrons to overcome the weight of the drop.

The number of electrons calculated coincides with those calculated from 16 to 25 , in the ninth column of Table II. This verifies the quantization of the electric charge.

Millikan also used a stopwatch and his data shows them in columns 2 and 3, in the 2 he shows the time in the middle of the fall and in the 3 the total time of fall. In the absence of convection, column 3 must be twice the value of column 2. Small differences show how small the convection is. Columns 3 and 4 should be the same, within their uncertainties. The timer shows an accuracy of 0.1 seconds, an accepted value for an instrument controlled by a finger. The instrument used to measure column 4 has a resolution of .002 seconds. Now we can use cameras of 1000 frames/second to measure thousandths of a second. We can interpret the chronometer readings as an independent corroboration. Figure 4 shows the sum of chronometer speeds between $\mathrm{Vo}=5.485 \times 10^{-}$ ${ }^{5} \mathrm{~m} / \mathrm{s}$, the same value used before.

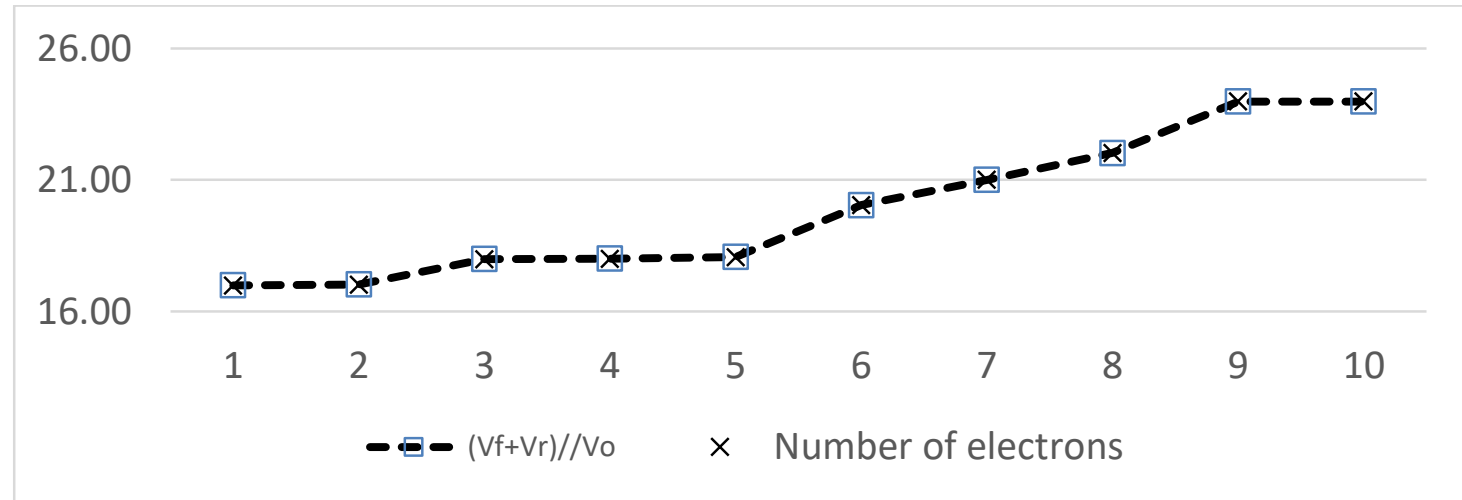

Fig. 4. The 10 data measured with a chronometer show the quantization of the charge and the number of electrons of each drop. The data is the same and only one graph is seen. 
Vol.8, Issue 2, pp.74-81, February 2020

Published by ECRTD- UK

Print ISSN: ISSN 2054-6351

Online ISSN: ISSN 2054-636X

The same value of $\mathrm{K}=2.92 \times 10^{-15} \mathrm{Cs} / \mathrm{m}$ was used to calculate the charge. Taking e = $1,602 \times 10^{-19} \mathrm{C}$ the same graph is obtained for the number of charges. Interpreting its data with the stopwatch produced the same results.

Considerations about drop mass and fall time.

The minimum droplet size available will depend on the droplet atomizer used. The measurements should be made using the slowest drop. By measuring its rate of fall, its radius can be calculated using the viscosity at the right temperature, using the viscosity effective value reduces it about 5\%? With the radius "a" the density, the mass of the drop is obtained. Knowing its weight in Newtons one can calculate the electrical force and estimate the minimum number of electrons needed to overcome gravity. Table III shows an example.

\begin{tabular}{|c|c|c|c|c|c|c|c|}
\hline data & $\begin{array}{l}\text { time } \\
\text { fall }\end{array}$ & vel. fall & $\begin{array}{l}\text { radius } \\
\mathrm{m}\end{array}$ & $\begin{array}{c}\text { Mass } \\
\mathrm{kg}\end{array}$ & $\begin{array}{c}\text { Weight } \\
\mathrm{N}\end{array}$ & $\begin{array}{l}\text { Electric } \\
\text { Force }\end{array}$ & $\begin{array}{l}\text { Min. } \\
\text { Num. e }\end{array}$ \\
\hline & & & $1.00 \mathrm{E}-$ & $3.82 \mathrm{E}-$ & 3.74E- & & \\
\hline fall $\mathrm{m}$ & 120 & 0.000108333 & 06 & 15 & 14 & $4.01 \mathrm{E}-14$ & 1 \\
\hline 0.013 & 110 & 0.000118182 & $\begin{array}{c}1.05 \mathrm{E}- \\
06\end{array}$ & $\begin{array}{c}4.35 \mathrm{E}- \\
15\end{array}$ & $\begin{array}{c}4.26 \mathrm{E}- \\
14\end{array}$ & 8.01E-14 & 2 \\
\hline density & 100 & 0.00013 & $\begin{array}{c}1.10 \mathrm{E}- \\
06\end{array}$ & $\begin{array}{c}5.02 \mathrm{E}- \\
15\end{array}$ & $\begin{array}{c}4.92 \mathrm{E}- \\
14\end{array}$ & 8.01E-14 & 2 \\
\hline 900 & 90 & 0.000144444 & $\begin{array}{c}1.16 \mathrm{E}- \\
06 \\
1.23 \mathrm{E}-\end{array}$ & $\begin{array}{c}5.88 \mathrm{E}- \\
15 \\
7.01 \mathrm{E}-\end{array}$ & $\begin{array}{c}5.76 \mathrm{E}- \\
14 \\
6.87 \mathrm{E}-\end{array}$ & 8.01E-14 & 2 \\
\hline Viscosity & 80 & 0.0001625 & $\begin{array}{c}06 \\
1.31 \mathrm{E}-\end{array}$ & $\begin{array}{c}15 \\
8.57 \mathrm{E}-\end{array}$ & $\begin{array}{c}14 \\
8.39 \mathrm{E}-\end{array}$ & $8.01 \mathrm{E}-14$ & 2 \\
\hline $1.82 \mathrm{E}-5$ & 70 & 0.000185714 & $\begin{array}{c}06 \\
1.42 \mathrm{E}-\end{array}$ & $\begin{array}{c}15 \\
1.08 \mathrm{E}-\end{array}$ & $\begin{array}{c}14 \\
1.06 \mathrm{E}-\end{array}$ & $1.20 \mathrm{E}-13$ & 3 \\
\hline g & 60 & 0.000216667 & $\begin{array}{c}06 \\
1.56 \mathrm{E}-\end{array}$ & $\begin{array}{c}14 \\
1.42 \mathrm{E}-\end{array}$ & $\begin{array}{c}13 \\
1.39 \mathrm{E}-\end{array}$ & $1.20 \mathrm{E}-13$ & 3 \\
\hline 9.8 & 50 & 0.00026 & $\begin{array}{c}06 \\
1.74 \mathrm{E}-\end{array}$ & $\begin{array}{c}14 \\
1.98 \mathrm{E}-\end{array}$ & $\begin{array}{c}13 \\
1.94 \mathrm{E}-\end{array}$ & $1.60 \mathrm{E}-13$ & 4 \\
\hline Voltage & 40 & 0.000325 & $\begin{array}{c}06 \\
2.01 \mathrm{E}-\end{array}$ & $\begin{array}{c}14 \\
3.05 \mathrm{E}-\end{array}$ & $\begin{array}{c}13 \\
2.99 \mathrm{E}-\end{array}$ & $2.00 \mathrm{E}-13$ & 5 \\
\hline 4000 & tion30 & 0.000433333 & $\begin{array}{c}06 \\
2.46 \mathrm{E}-\end{array}$ & $\begin{array}{c}14 \\
5.61 \mathrm{E}-\end{array}$ & $\begin{array}{c}13 \\
5.50 \mathrm{E}-\end{array}$ & $3.20 \mathrm{E}-13$ & 8 \\
\hline Separa. & 20 & 0.00065 & $\begin{array}{c}06 \\
3.48 \mathrm{E}-\end{array}$ & $\begin{array}{c}14 \\
1.59 \mathrm{E}-\end{array}$ & $\begin{array}{c}13 \\
1.55 \mathrm{E}-\end{array}$ & $5.61 \mathrm{E}-13$ & 14 \\
\hline 0.016 & 10 & 0.0013 & 06 & 13 & 12 & $1.56 \mathrm{E}-12$ & 39 \\
\hline $\begin{array}{l}\text { Elec. } \\
\text { field }\end{array}$ & 8 & 0.001625 & $\begin{array}{c}3.89 \mathrm{E}- \\
06\end{array}$ & $\begin{array}{c}2.22 \mathrm{E}- \\
13\end{array}$ & $\begin{array}{c}2.17 \mathrm{E}- \\
12\end{array}$ & $2.20 \mathrm{E}-12$ & 55 \\
\hline 250000 & 6 & 0.002166667 & $\begin{array}{c}4.49 \mathrm{E}- \\
06 \\
5.50 \mathrm{E}-\end{array}$ & $\begin{array}{c}3.41 \mathrm{E}- \\
13 \\
6.27 \mathrm{E}-\end{array}$ & $\begin{array}{c}3.35 \mathrm{E}- \\
12 \\
6.15 \mathrm{E}-\end{array}$ & $3.36 \mathrm{E}-12$ & 84 \\
\hline e & 4 & 0.00325 & $\begin{array}{c}06 \\
7.78 \mathrm{E}-\end{array}$ & $\begin{array}{c}13 \\
1.77 \mathrm{E}-\end{array}$ & $\begin{array}{c}12 \\
1.74 \mathrm{E}-\end{array}$ & $6.17 \mathrm{E}-12$ & 154 \\
\hline $1.60 \mathrm{E}-19$ & 2 & 0.0065 & 06 & 12 & 11 & $1.74 \mathrm{E}-11$ & 435 \\
\hline
\end{tabular}


Vol.8, Issue 2, pp.74-81, February 2020

Published by ECRTD- UK

Print ISSN: ISSN 2054-6351

Online ISSN: ISSN 2054-636X

The first data column is that used by Millikan, but it was calculated with a lower voltage. For times of fall less than 10 seconds, the minimum number of electrons necessary to overcome the force of gravity is too large. With this data one can choose the most suitable voltage or cancel the experiment. It is convenient, as Millikan did, to measure the velocities several times to estimate the uncertainty in the charge and corroborate its presence in integer multiples.

\section{Summary.}

Analyzing and interpreting Millikan's data is an excellent exercise for students. It also allows us to understand why school experiments limited by available equipment to calculate the electron charge by using drop times shorter than 100 seconds are complicated to interpret. The number of electrons per drop needed to overcome the weight of the relatively large drops is far too large for comfort.

\section{References}

Air viscosity: www.engineersedge.com/physics/viscosity of air dynamic and kinematic 14483.htm consulted 2/12/2019

Halyo, V. et al, (1999) Search for Free Fractional Electric Charge Elementary Particles, SLAC-PUB-8283, arXiv.org > hep-ex > arXiv:hep-ex/9910064

file:///C:/Users/river/Desktop/Documents/Millikan/9910064.pdf

Heald, M.A. (1974) Millikan Oil-Drop Experiment in the Introductory Laboratory, American Journal of Physics 42, 244; doi: 10.1119/1.1987656

Jones, R.C. (1995) "The Millikan oil-drop experiment: Making it worthwhile," Am. J. Phys. 63, 970-977. https://doi.org/10.1119/1.18001

Kapuska, J.I. (1975) Best measuring time for a Millikan oil drop experiment, American Journal of Physics 43, 799; doi: 10.1119/1.9710

Melissinos, A.(1966) Experiments in Modern Physics, Academic Press, New York, pag. 2-7.

Millikan, R.A.(1913) "On the elementary electric charge and the Avogadro constant," Phys. Rev. (Series II) 2, 109-143 (Aug. 1913). https://doi.org/10.1103/PhysRev.2.109,.-

Nobel Foundation, (1960) Nobel Lectures in Physics 1922-1941, Elsevier, pag 4-9.

\section{Acknowledgment}

Many thanks to Teodoro Halpern by improving the article 